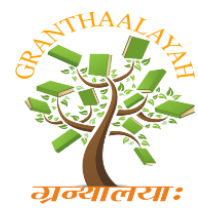

INTERNATIONAL JOURNAL OF RESEARCH GRANTHAALAYAH

A knowledge Repository

Science

\title{
FUNCTIONAL RECOVERY OF ELBOW COMPLEX IN MONTEGGIA FRACTURE-DISLOCATION - PRESENTATION OF CASE
}

\author{
M. V. Becheva ${ }^{* 1}$ \\ ${ }^{* 1} \mathrm{PhD}$, Medical University - Plovdiv, Medical College, BULGARIA
}

\begin{abstract}
The treatment of elbow joint fractures is a serious medical and social problem due to frequent complications and impairment of the ability of self-service and performance of various household and labour activities. We needed evidence as to which exercises were appropriate in the treatment of patients with fracture elbow-Monteggia.

The aim of the presented clinical case is to examine the effectiveness of the applied kinesitherapeutic methodology in Monteggia fracture-dislocation treated surgically by internal fixation.

Kinesitherapy was carried out in two phases (maximally and moderately protective), and as a result of the applied means of functional recovery, there was achieved a good elbow reintegration in the motor circuit of upper limb.

There was observed a small deficit in terms of flexion and extension in the right elbow joint, which should be ascribed to the lack of artromot, as well as to insufficient patient motivation. Global functions reported by MEPS were 84/100.
\end{abstract}

Keywords:

Kinesitherapy, Monteggia fracture.

Cite This Article: M. V. Becheva, "FUNCTIONAL RECOVERY OF ELBOW COMPLEX IN MONTEGGIA FRACTURE-DISLOCATION - PRESENTATION OF CASE" International Journal of Research - Granthaalayah, Vol. 4, No. 4 (2016): 20-26.

\section{INTRODUCTION}

Fractures in the elbow joint are frequent - they represent $7 \%$ of all fractures with $1 / 3$ of them affecting the distal humerus, $33 \%$ - the head and the neck of the radius and $20 \%$ - the olecranon. Other common fractures include the proximal ulna, the coronoid process and the Monteggia fracture (Barenholtz et al. 2000).

The treatment of elbow joint fractures is a serious medical and social problem due to frequent complications and impairment of the ability of self-service and performance of various household and labour activities. Difficult to recover, contractures are one of the main problems for kinesitherapeutic practice after fractures of the elbow joint (Matev et al., 1977). 
These contractions are the result not only of trauma affecting bone and soft tissues lying around and the subsequent immobilization of the joint, but also of surgery and the difficulty to recover the congruence of articular surfaces (Asly, 2005).

Pain and increased muscle tone m.biceps brachii and m.triceps brachii play an essential role in the restriction of movement. Compensatory mechanisms of the deficit in the mobility of the elbow complex are limited and do not help to improve the functionality of the affected limb (Bankov, 1971).

\section{AIM OF THE STUDY}

The aim of the presented clinical case is to render the effectiveness of the applied kinesitherapeutic methodology in Montggia fracture-dislocation treated surgically by internal fixation.

\section{CASE REPORT}

We have presented the case of a 35 year old female patient with a fracture of the ulna with dislocation of the radial head in the right elbow joint as a result of direct trauma from a fall on the ulnar side of the right forearm. (Bado classification - II type). The patient was treated surgically with intramedullary fixation.

The case history was taken according to data obtained from the patient. A radiographic scanning was performed. The patient reported no attendant and past illnesses.

The kinesitherapeutic procedure was held after an immobilisation period of maximal and moderate protective phase. The procedure lasted 30 days.

\section{RESULTS}

Table 1: Centimeter measurement of upper limbs

\begin{tabular}{|l|l|l|l|l|}
\hline \multirow{2}{*}{$\begin{array}{l}\text { Centimeter } \\
\text { measurement }\end{array}$} & \multicolumn{3}{|l|}{ Beginning } & \multicolumn{2}{l|}{ End } \\
\cline { 2 - 5 } & dex & sin & dex & sin \\
\hline Arm & 37 & 39 & 39 & 39 \\
\hline Forearm & 32,5 & 31 & 31,5 & 31 \\
\hline Elbow joint & 29 & 27 & 27 & 27 \\
\hline Wrist joint & 24,5 & 23 & 23 & 23 \\
\hline
\end{tabular}

Table 2: Joint angle measurement of elbow and radio-ulnar joints

\begin{tabular}{|l|l|l|l|l|l|l|l|l|}
\hline $\begin{array}{l}\text { Joint angle } \\
\text { measurement }\end{array}$ & \multicolumn{4}{l|}{ Beginning } & \multicolumn{4}{l|}{ End } \\
\hline & \multicolumn{2}{|l|}{ flexion } & \multicolumn{2}{l|}{ extension } & \multicolumn{2}{l|}{ flexion } & \multicolumn{2}{l|}{ extension } \\
\hline Elbow & dex & $\sin$ & $\operatorname{dex}$ & $\sin$ & $\operatorname{dex}$ & $\sin$ & $\operatorname{dex}$ & $\sin$ \\
\hline
\end{tabular}




\begin{tabular}{|l|l|l|l|l|l|l|l|l|}
\hline joint & 65 & 120 & -15 & 0 & 110 & 120 & -5 & 0 \\
\hline \multirow{3}{*}{$\begin{array}{l}\text { Radio-ulnar } \\
\text { joint }\end{array}$} & \multicolumn{2}{l|l|l|}{ pronation } & \multicolumn{2}{l|}{ supination } & \multicolumn{2}{l|}{ pronation } & \multicolumn{2}{l|}{ supination } \\
\cline { 2 - 9 } & $\operatorname{dex}$ & $\sin$ & $\operatorname{dex}$ & $\sin$ & $\operatorname{dex}$ & $\sin$ & $\operatorname{dex}$ & $\sin$ \\
\cline { 2 - 9 } & 45 & 90 & 25 & 90 & 87 & 90 & 75 & 90 \\
\hline
\end{tabular}

Upon admission of the patient, we found that active movements in the elbow joint were limited. The patient reported the existence of pain (identifying it with 4 on SAC) in the course of flexion, extension in the right elbow joint, and pain evaluated with 5 on SAC in carrying out pronation and supination in the radio-ulnar joints of the right upper limb.

Using manual muscle testing, we ascertained a difference in muscle strength for flexion and extension as well as for pronation and supination that gave us reason to put a score of (3 -) on MMT for muscle groups performing the studied movements.

Centimeters measurements helped us establish a swollen right elbow joint, right forearm and wrist. At the level of elbow joint we found a difference of two centimeters and at the level of forearm and wrist of about $1.5 \mathrm{~cm}$ (tab.1). As for changes in the volume of movement between the beginning and end results, we were able to report a significant difference in both sagittal plane and rotator movements.

At the beginning of the study (immediately after removal of immobilization), the extension showed a deficit of $15^{\circ}$, and at the end of the applied methodology it reached a deficit of $5^{\circ}$.

Folding in the elbow joint increased by an average of $45^{\circ}$. At the beginning of treatment, the possible flexion was $65^{\circ}$, and at the end it reached $110^{\circ}$.

A significant increase in values was observed both in supination $\left(50^{\circ}\right)$ and pronation $\left(42^{\circ}\right)$ with respect to the rotator movements. From $25^{\circ}$ at the beginning, supination reached $75^{\circ}$ at the end of the study, and pronation from $45^{\circ}$ increased to $87^{\circ}$ (Table. 1)

Data from centimeter measurement of upper limb (Table 2) show that the most significant changes occurred in the circumference of the arm. The difference in values between the initial and final study is more than $2 \mathrm{~cm}$., which testifies to improved muscle trophic in the arm.

In the area of forearm, the final results were not as convincing, since the difference between the values of the circumference of forearm at the beginning and at the end was about one centimeter.

We assume that this is due to the initial swelling, which was localized in the area of the elbow joint and forearm and which did not allow us to take into account the actual values of muscle hypotrophy in the lower arm at the beginning of the study and the subsequent recovery of muscle volume by the end of the study.

\section{DISCUSSION}

Functional recovery takes centre stage in the rehabilitation of intra-articular fractures of the elbow joint. The restoration aims to prevent any stiffness and reintegrate the elbow in the motor circuit of upper limb (Hotchkiss et al., 1992). 
At the beginning of the maximal protective layer, a swelling, muscle guard and pain in the right elbow joint were registered, the result of which was observed for impaired joint mobility and decreased muscle strength.

To overcome post traumatic swelling and pain and to improve joint trophic we applied manual lymphatic drainage, proximally and distally to the joint, careful active and assisted movements from a relieved starting position in painless volume in view of the manual assistance and control of the active movement at reduced muscle and stabilizer function of the elbow joint (Popov et al., 2007). The dosage of each movement was 1-2 minutes at a slow pace until pain threshold was reached.

We applied treatment with elevation of the limb, cryotheraphy - 2-3 times daily (spreads with ice cubes) for about 3-5 minutes. We had in mind that overcoming the swelling has a direct impact on reducing the compression in the joint and pain perception, which in turn reduces muscle reflector guard and increases the ability to perform movement in the joint (Karaneshev et al., 1999). In this phase we also applied minimal isometric contractions from a painless position for flexors and extensors in the elbow joint. These contractions aimed at overcoming the consequences of the restraint and restoring the motor habit.

During the first three weeks we were careful about the last degrees of supination and extension, as supination was worked from flexion in the elboww joint, while extension from pronation (Winter et al., 2007). We applied Lewit PIR technique, in order to prevent muscle imbalance and joint contractures installation.

In the maximal protective phase we implemented an active exercise in full measure of movement and exercises against resistance for shoulder and wrist joint, not allowing compensatory mechanisms, adhering to a correct scapula-humeral rhythm (Becheva, 2015).

After the tenth kinesitherapeutic treatment, swelling and muscle guard were significantly reduced and the volume of movement was restored, but not within normal limits.

To prevent adhesions and improve periarticulatory gliding, we performed slow and gentle active and assisted movements to restore normal arthrokinematics and to increase the volume of movement in the elbow joint (Sokolov, 1991).

To restore the accessory mobility of the elbow segments, we used mobilization and stretching that there is no risk of too stressful healing fragments (Popov, 2006).

Due to a lack of intra-articular pain we applied passive oscilations with tractions along the axis of the forearm at the end of the possible range of motion and muscle inhibition techniques for relaxation of the segment. The application of reciprocal inhibition produced a very good effect.

At the end of the maximal protective layer we applied isotonic exercises after reaching $70^{\circ}$ flexion in the elbow joint in an open kinematic chain. Manual resistance enabled us to specify the dosage of effort and the movement direction control (Mariette-Recule, 1997). 
The dosage was 5-6 repetitions in 2-3 sets with submaximal resistance. Originally we included flexors, extensors, pronators and supinators analytically, as the resistance was distal to the forearm with the arm pinned to the body. Then we exerted distal resistance without fixation of the arm, which caused simultaneous contraction of the elbow and shoulder muscles. We applied rhythmic stabilization for flexors, extensors, and pronators and supinators from different angles of movement.

The moderate protective phase or the phase of active controlled increase of the volume of movement was characterized by pain after reaching the tissue tension, disclosure of soft tissue contractures, and impaired mobility in the right accessory elbow joint.

According to Popov, the main factors limiting the full recovery of joint mobility are the formed during immobilization contractures and adhesions (Popov, 2009).

The classic stiffness in the elbow joint is defined as limitation of movement in the joint resulting in ankylosis causing total loss of motion (Schindler et al., 1991).

According to Allieu post-traumatic stiffness in the elbow is defined as limiting in the passive sector of the amplitude of movement as a result of accidental or surgical trauma (Allieu, 1989).

The elbow joint is not a supporting one and therefore the pain symptoms are secondary. Therefore there is great opposition to passive and active range of motion. Two sectors of movement may be exercised independently: flexion - extension and pronosupination. These two sectors of movement may be restricted together or alone (Kelberine et al., 2006: Tan et al., 2006).

The deficit of movement dominated the extension sector. The main emphasis in this period was the restoration of joint kinematics. In order to restore the normal arthrokinematics and overcome the soft tissue contractures, we applied mobilization stretching, muscle - inhibition techniques (Janda post-facilitation stretching, reciprocal inhibition; multiangular rhythmic stabilization of elbow and shoulder joints).

Musculo-inhibitory techniques (Janda post fasilitatsionen stretching and reciprocal inhibition) were applied to specific pathological changes in the muscles depending on the individual characteristics of the regenerative process.

They contributed to the elimination of muscular guard, which was one of the main limiting factors of normal movement in the joint (Barakova et al., 2007).

We included the applied mobilization stretching early because this technique is pain-reducing and also because of the atraumatic extension of passive periarticular tissues (Slantchev et al., 1986).

Gradually, we included exercises against resistance in combined and diagonally-spiral patterns of movement. With the implementation of these exercises we achieved the most effective integration of the operationally traumatized segment and as well as the former boost coordination on complex activities of the upper limb in daily life (Sokolov, 1991). 
At the end of this phase we included low-intensity movement activities (dressing, grooming, reaching, holding, pushing), in the absence of compensatory and substitution movements.

In the moderately protective phase we trained the patient in autopassive exercises which she performed after resolution of the symptoms of muscular guard.

The study of global final results were evaluated by (MEPS) Mayo Elbow Performance Score, as a result achieved was $84 / 100$, which speaks of a good recovery of upper limb function.

The pronospination in radio-ulnar joints recovered almost completely, but there was a deficit in extension and flexion at the elbow joint.

\section{CONCLUSION}

We have attributed the reported deficit in flexion and extension after kinesitherapy to the lack of use of an artromot and partly to the lack of motivation of the patient.

The good functional results in the restoration of the functional gestures of the upper limb were due to the early start of kinesitherapeutic procedures and well-selected means and their combination.

We can conclude that the so-attached kinesitherapy gives good therapeutic effects and is suitable for restoring the functions of the upper limb in intra-articular fractures of the elbow joint.

\section{REFERENCES}

[1] Barenholtz, A., Wolff, A. Elbow and Rehabilitation Fractures. Orthop Phys Ther Cin North Am, 2000, 10, 525-39 https://books.google.bg/books

[2] Matev, Iv., St. Bankov. Rehabilitation of hand damage. Medicine and Physical Training Sofia 1977, 32-38.

[3] Asly, M. La reeducation des raideurs post-traumatiques du coude .Bibliothèque Universitaire Mohamed Sekkat - Casablanca, Maroc 2005. http://rissalaty.univcasa.ma:8080/xmlui/handle/123456789/1299?show=full

[4] Bankov, St. Index for a comprehensive assessment of the volume of movement of the elbow joint contractures. Kurortology and physiotherapy 1971 issue.4, 17.

[5] Hotchkiss, R., S. Davila. Rehabilitation of the Elbow. In Morrey B, Nickel VN (Eds). Orthopedic Rehabilitation. Churchill Livingstone, New York, 1992, 29.

[6] Popov, N., E. Dimitrova. Kinesitherapy in orthopedic diseases and injuries of the upper limb, NAV-PRESS, Sofia 2007, 219-250.

[7] Karaneshev, G., D. Miltcheva S. Yancheva. Diagnostics and research in therapeutic exercises, Sofia 1999, 46-49.

[8] Winter, M., C. Chuinard, C.Pelegri, J.-P. Pequignot, F.De Peretti. 144 Prise en charge standardisée des luxations du coude associées à une fracture non reconstructible de la tête radiale. Revue de Chirurgie Orthopédique et Réparatrice de l'Appareil Moteur 93, 7 November 2007, 99.

http://www.sciencedirect.com/science/article/pii/S003510400779517X?np= 
[9] Becheva. V. M. Kinesitherapy in diseases of the musculoskeletal system. Medical University - Plovdiv, 2015, 12-19.

[10] Sokolov, B. Therapeutic exercise in traumatology. Sofia 1991, 79-85.

[11] Popov, N. Kinesiology and pathokinesiology of the musculoskeletal system, NSA-PRESS, Sofia 2009, 39-51.

[12] Mariette-Recule, M. Luxations et instabilités du coude. Journées de Rééducation du Membre Supérieur et de la Main No13, France 1997 no 365 (58) (9 ref.), 27-29. http://rissalaty.univcasa.ma:8080/xmlui/handle/123456789/1299?show =full

[13] Schindler, A., B. Yaffe, A. Chetrit, M. Modan, J. Engel. Factors influencing elbow arthrolysis. Ann Chir Main Memb Super 1991, 10, 237-242. http://www.sciencedirect.com/science/article/pii/S0753905305802881

[14] Allieu, Y. Raideur et arthrolyse du coude. Rev Chir Orthop 1989, 1, 157-166.

[15] Kelberine, F., P. Landreau, J. Cazal. Traitement arthroscopique des raideurs du coude Arthroscopic Management of the Stiff Elbow. November 2006, 25 (1), S108-S113 http://www.sciencedirect.com/science/article/pii/S1297320306000588

[16] Tan,V., A. Daluiski, P. Simic, RN. Hotchikiss. Outcome of open release for posttraumatic elbow stiffness. J Trauma 2006, 61, 673-680.

[17] Barakova, P., P. Parashkevova, I. Stefanova. Kinesitherapy treatment in combined fractures of the elbow joint, coupled with endoprosthesis of the radial head, I-st Balkan Conference "Science, Education and Arts in the 21st Century", Blagoevgrad 2007, 20-25.

[18] Slantchev, P., L. Bonev, St. Bankov. A guidebook in kinesitherapy. Sofia 1986, 45-4. 